\title{
OHVIRA syndrome: a rare variant of mullerian duct anomaly
}

\section{Samar Rudra, Nidhi Dahiya*}

Department of Obstetrics and Gynaecology, MMIMSR, Mullana, Ambala, Haryana, India

Received: 28 October 2016

Revised: 08 November 2016

Accepted: 28 November 2016

\author{
*Correspondence: \\ Dr. Nidhi Dahiya, \\ E-mail: nidhidahiya12@yahoo.co.in
}

Copyright: () the author(s), publisher and licensee Medip Academy. This is an open-access article distributed under the terms of the Creative Commons Attribution Non-Commercial License, which permits unrestricted non-commercial use, distribution, and reproduction in any medium, provided the original work is properly cited.

\begin{abstract}
OHVIRA is a rare variety of congenital anomaly of mullerian duct. The syndrome includes uterus didelphys, obstructed hemivagina and ipsilateral renal anomaly, also known as Herlyn-Werner-Wunderlich (HWW) syndrome. A $15 y$ rs old girl was referred to our department with regular menstrual period and cyclic pain in lower abdomen of 5 6 months duration. USG and MRI established the final diagnosis of OHVIRA syndrome. Drainage of hematocolpos of obstructed hemivagina and excision of septum was done and patient was discharged under satisfactory condition to come for follow-up. Patient had her normal menses on 28/8/2015. A repeat USG was done which showed didelphus uterus with no collection in endometrial cavity.
\end{abstract}

Keywords: Congenital anomaly, OHVIRA, Mullerian duct

\section{INTRODUCTION}

OHVIRA is a rare variety of congenital anomaly of mullerian duct. The syndrome includes uterus didelphys, obstructed hemivagina and ipsilateral renal anomaly, also known as Herlyn-Werner-Wunderlich (HWW) syndrome. As patient may have normal menses so diagnosis is challenging. It was first reported in 1922. ${ }^{\circ}$ Usually patients present after menarche with pelvic pain and/or a pelvic mass and rarely, in later years, with primary infertility. Strong suspicion and knowledge of this anomaly are essential for a precise diagnosis. ${ }^{2}$ The triad of uterine didelphys, obstructed hemivagina, and ipsilateral renal agenesis, known as OHVIRA syndrome or HWW syndrome, is a congenital anomaly of Müllerian duct with associated mesonephric duct anomaly. ${ }^{3,4}$ This is a very rare but well documented variety of mullerian anomaly. A very few cases has been reported in the literature. They generally present at puberty with nonspecific symptoms, such as pelvic pain, recurrent severe dysmenorrhea, and a palpable mass associated with hematocolpos or hematometra. ${ }^{5}$ Hematocolpos or hematometra occurs with occlusion of vaginal canal due to the fusion the septum with the vaginal wall. ${ }^{6}$

\section{CASE REPORT}

A 15-year-old unmarried girl reported to Gynaec OPD with complains of cyclic pain in lower abdomen of 5-6 months duration. Her menarche dated 1 year back. Her menstrual cycles were regular lasting for 3-4 days and occurring at 30 days interval associated with dysmenorrhea. Systemic examination did not reveal any abnormality. Inspection of external genital showed an intact hymenal opening without any bluish discolouration. Per rectal examination revealed a cystic mass of $8 \times 6 \mathrm{cms}$ size on right side and uterus on left side, palpable through the anterior rectal wall. Patient's vitals were stable. Routine investigations were within normal range. Trans-abdominal USG of the pelvis revealed double uterus, a collection of $7.5 \times 6.3 \mathrm{cms}$ size with homogenous echo in region of vagina. Bilateral ovaries were separately visualized but right kidney was not visualised. With these clinical and ultrasound finding OHVIRA syndrome was suspected and a MRI was asked for to confirm our diagnosis. MRI showed uterine didelphys, right uterus $5.2 \times 2.6 \mathrm{cms}$ with endometrial thickness $5.6 \mathrm{~mm}$ and left uterus measures $4.7 \times 2 \mathrm{cms}$ with endometrial thickness $6 \mathrm{~mm}$. Ballooned out right vaginal cavity markedly showing complex collection appearing heterogeneously hypointense measuring $9.5 \mathrm{cms}$ (SI) X 
$4.7 \mathrm{~cm}$ (ML) $\mathrm{X} \quad 4.8 \mathrm{~cm}$ (AP) communicating with endocervical canal with minimal fluid in endometrial cavity on the right side and a normal collapsed left vaginal canal found. Right kidney was absent. A diagnosis of OHVIRA syndrome was confirmed.

After taking consent from parents she was taken up for surgery under spinal anaesthesia. Nick given on hymen at 4,8 , and 12 O' clock position. Space created in introitus. 1 finger vaginal examination done. Left side cervix palpated. Haematocolpos of the blind vagina was felt as a buldge in upper vagina on the right side through the intravaginal septum. The vertical vaginal septum in upper vagina was incised draining dark coloured collected blood. Edge of the incision held and about $3 \times 2 \mathrm{cms}$ of vaginal septum excised creating a free communication between the patent upper portion of right hemivagina and normal left vaginal canal.

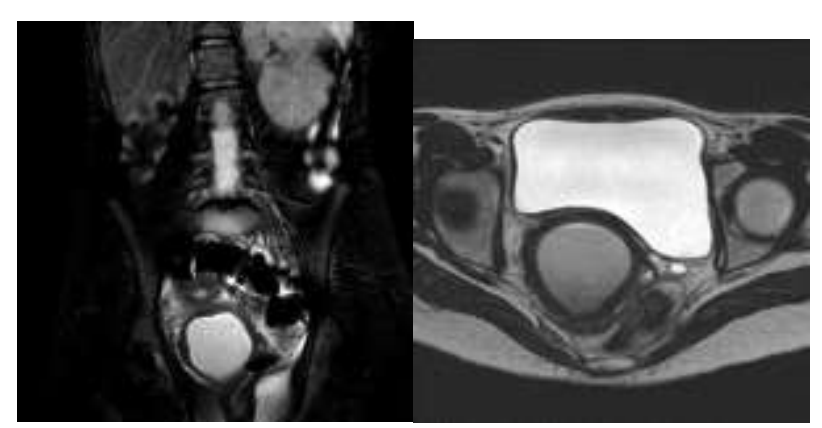

Figure 1: Uterine didelphys ballooned out right vaginal cavity markedly showing complex collection appearing heterogeneously hypointense communicating with endocervical canal with minimal

fluid in endometrial cavity on the right side and a normal collapsed left vaginal canal found. Right kidney was absent.

\section{Intra operative images}

Patient withstood the procedure well and recovered well post operatively. USG done before discharge revealed no collection or free fluid in vagina. On follow up patient told that she had her normal menses on 28/8/2015. A repeat USG was done which showed didelphus uterus with no collection in endometrial cavity.

\section{DISCUSSION}

Although the true incidence of mullerian defects is about $1.1-3.5 \%$. It is believed to be much higher (around 25\%) in women with recurrent miscarriages and subfertility. Renal agenesis and uterus didelphys are strongly associated with each other $(81 \%)^{7}$

The incidence of OHVIRA syndrome is very rare and only isolated case reports have been published. In literature it is reported to be about $0.16-10 \%$ of all mullerian duct anomalies. ${ }^{8}$ Many present in an early infancy with collection of secretions in the obstructed vagina under influence of maternal hormones; and others within 1-2 years of onset of menarche due to development of hematocolpos, hematometra, or even hematosalpinx. These patients also have dysmenorrhea, which later evolves into persistent pelvic pain, pelvic adhesion, endometriosis and even infertility in later life.

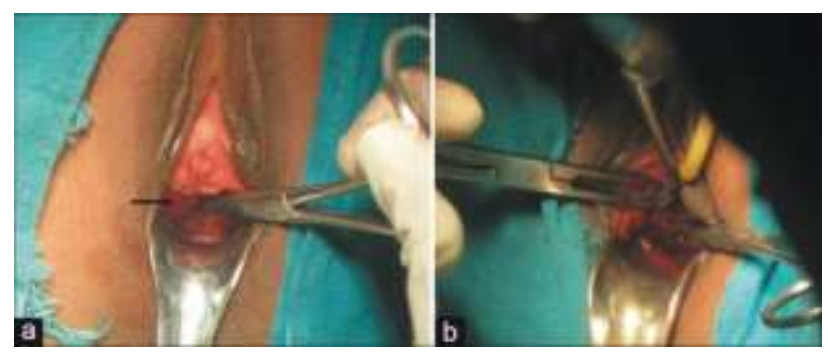

Figure 2: Intra operative images.

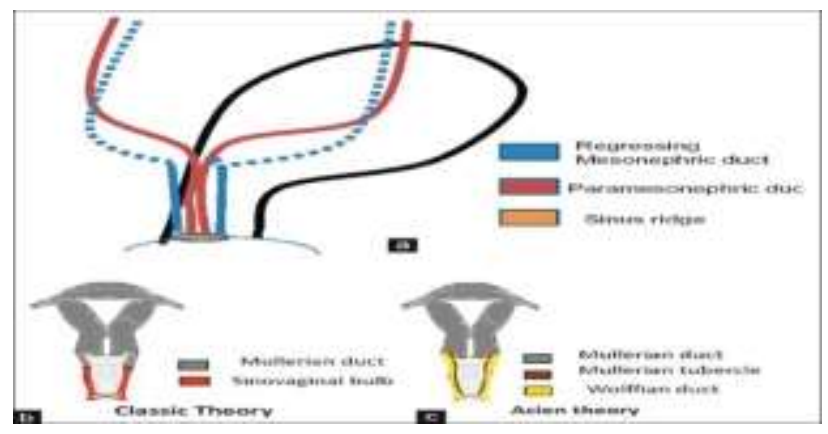

Figure 3: (a) Embryological development of the female urogenital system (b) Classic theory of development of uterus and vagina (c) Acien theory of development of uterus and vagina.

Vaginal embryonic development has become a topic of hot debate since a new theory of vaginal origin has been published by Acien. ${ }^{9}$ Acien and Acien in their extensive analytical work proposed a new classification of female genital tract malformation.

According to the classical theory of American Fertility society (AFS) vagina develops mainly from mellerian duct and partly from urogenital sinus by canalization of vaginal plate which is formed by mullerian tubercle and sinovaginal bulb. Classic theory is somehow inadequate to explain complex female urogenital anomalies like OHVIRA syndrome and their coexistence with ranal anomalies. According to Acien the uterus and cervix were derived from fused paired paramesonephric ducts (2nd part) and divergent distal paramesonephric ducts (3rd part), the vagina is completely of mesonephric (wolffian) origin but its lining did reveal mullerian cells derived from mullerian tubercle. Hence, paramesonephric ducts do not contribute to formation of the vagina although mullerian tubercle does, such that the vagina is lined by cells from mullerian tubercle. [Figure 1c] This theory has been further reinforced by data published by Sánchez. ${ }^{10}$ in his experiments with female rats using histoimmunochemistry techniques. Acein's new theory 
postulated that appropriate development, fusion and resorption of the separating wall between both mullerian duct seems to be induced by wolffian duct which are located on both side of the mullerian duct and act as a guide element. The ureteral bud sprout from the opening in urogenital sinus of the wolffian duct. Any absence or distal injury to one of these ducts will give rise to renal agenesis, a blind or athretic ipsilateral hemivagina and uterine anomalies (fusion or resorption defects) due to failure of inducing function of injured mesonephric duct. Thus the Acien's theory explains complex urogenital anomalies like OHVIRA syndrome. The old American Fertility society (AFS) classification is associated with serious limitation of effective categorization of female genital anomalies. New classification of Acein et al can categorize various female genital anomalies which are difficult to categorize by AFS system. Recently this has been further improved and simplified by European Society of Human Reproduction and Embryology (ESHRE)/European Society for Gynaecological Endoscopy (ESGE) Classification of female genital tract congenital anomalies. These new classification has improved our understanding of various female urogenital anomalies which is a prerequisite for their appropriate treatment.

Treatment of this rare anomaly remains essentially surgical. After surgical correction patient usually have a normal menstrual function, sexual life as well as reproductive function.

\section{CONCLUSION}

OHVIRA syndrome is a rare variety of female urogenital anomaly, requires knowledge of this abnormality to raise suspicion when young girls present with dysmenorrhea. Generally USG and MRI clinch the diagnosis. A surgical correction restores normalcy of menstrual, sexual and reproductive functions.

\section{Funding: No funding sources Conflict of interest: None declared \\ Ethical approval: Not required}

\section{REFERENCES}

1. Shah DK, Laufer MR. Obstructed hemivagina and ipsilateral renal anomaly(OHVIRA) syndrome with a single uterus. Fertility and Sterility. 2011;96:e39-41.

2. Mandava A, Prabhakar RR, Smitha S.OHVIRA syndrome (obstructed hemivagina and ipsilateral renal anomaly) with uterus didelphys, an unusual presentation: an unusual presentation. J Pediatr Adolesc Gynecol. $2012 ; 25: \mathrm{e} 23-5$.

3. Beer WM, Carstairs SD. Herlyn Werner Wunderlich syndrome: an unusual presentation of acute vaginal pain. J Emerg Med. 2013;45:541-3.

4. Gholoum S, Puligandla PS, Hui T, Su W, Quiros E, Laberge JM. Management and outcome of patients with combined vaginal septum, bifid uterus, and ipsilateral renal agenesis(Herlyn-Werner-Wunderlich syndrome). J Pediatr Surg. 2006;41:987-92.

5. Del Vescovo R, Battisti S, Di Paola V. Herlyn-WernerWunderlich syndrome: MRI findings, radiological guide (two cases and literature review), and differential diagnosis. BMC Med Imaging. 2012;9;12:4.

6. Hulya Ozturk, Emine Dagistan, Tulay Ozlu. Role of OHVIRA syndrome in renal agenesis: a case report. Ped Urol Case Rep. 2014;1(2):5- 11 .

7. Sunil K Bajaj, Ritu Misra, Brij B Thukral, and Rohini Gupta. OHVIRA: Uterus didelphys, blind hemivagina and ipsilateral renal agenesis: Advantage MRI. J Hum Reprod Sci. 2012;5(1):67-70.

8. Cox D, Ching BH. Herlyn-Werner-Wunderlich syndrome: a rare presentation with pyocolpos. Journal of Radiology Case Reports. 2012;6(3):9-15.

9. Acién P. Embryological observations on the female genital tract. Hum Reprod. 1992;7:437-45.

10. Sánchez-Ferrer ML, Acién MI, Sánchez del Campo F, Mayol-Belda MJ, Acién P. Experimental contributions to the study of the embryology of the vagina. Hum Reprod. 2006;21:1623-8.

Cite this article as: Rudra S, Dahiya N. OHVIRA syndrome: a rare variant of mullerian duct anomaly. Int J Reprod Contracept Obstet Gynecol 2017;6:3268. 